This item was submitted to Loughborough's Research Repository by the author.

Items in Figshare are protected by copyright, with all rights reserved, unless otherwise indicated.

\title{
Financial fair play and competitive balance in the Premier League
}

PLEASE CITE THE PUBLISHED VERSION

http://dx.doi.org/10.1108/SBM-10-2016-0058

\section{PUBLISHER}

(c) Emerald Publishing

\section{VERSION}

AM (Accepted Manuscript)

\section{PUBLISHER STATEMENT}

This work is made available according to the conditions of the Creative Commons Attribution-NonCommercialNoDerivatives 4.0 International (CC BY-NC-ND 4.0) licence. Full details of this licence are available at: https://creativecommons.org/licenses/by-nc-nd/4.0/

\section{LICENCE}

CC BY-NC-ND 4.0

\section{REPOSITORY RECORD}

Freestone, Christopher John, and Argyro Elisavet Manoli. 2019. "Financial Fair Play and Competitive Balance in the Premier League". figshare. https://hdl.handle.net/2134/24606. 


\title{
Financial fair play and competitive balance in the Premier League
}

Christopher John Freestone, Loughborough University

Argyro Elisavet Manoli, Loughborough University, e.a.manoli@lboro.ac.uk

\begin{abstract}
Purpose: The introduction of financial fair play regulations in 2011 was accompanied by criticism that they would have an adverse effect on competitive balance in European football. Counter-points were also expressed, suggesting that the opposite would occur; that they would actually increase competitive balance through reducing the importance of financial power. The lack of clarity and cohesion on this issue prompted this study, which examines the effect FFP has had on competitive balance in the English Premier League.

Design: The analysis conducted uses the Herfindahl Index of Competitive Balance as the primary method, and is supported by standard deviation of points analysis and a Scully-Noll ratio analysis, which together provide an indication of the level of competitive balance for each of the past 21 seasons, from 1995/96 to 2015/16. This examination allows for the trends in competitive balance to be identified, with emphasis drawn on the seasons after the introduction of the regulations.
\end{abstract}

Findings: The results provide no indication that FFP regulations have resulted in a decline in competitive balance in the EPL, instead hinting that a positive effect may have been caused. This positive effect exceeds the primary aim of the regulations and underlines their importance in the future stability of club football.

Originality/value: While underlining the need for further research on the topic, this study provides the first insights to the effects of FFP regulations on competitive balance in the EPL. These insights would support the view that FFP initiatives have begun to shift the focus of sporting competition away from financial strength towards more natural means of competition such as efficiency, innovation and good management.

\section{Keywords:}

Club football, European football, football finance, sport financial management 


\section{Introduction}

There exists a growing concern about the financial plight of European club football, which, despite ever-increasing revenues, continually fails to collectively break-even (Storm and Nielsen, 2012). Europe's top-division clubs combined produced $€ 13.2$ billion in revenue for the financial year of 2011, yet the same 734 clubs made a combined net loss of $€ 1.7$ billion for the same period (UEFA, 2011; Franck, 2014). Net losses among the 734 clubs increased by 760\% over the five-year period between 2006 and 2011 (Franck and Lang, 2013), with $55 \%$ of clubs reporting net losses in 2011 (UEFA, 2011). Further, 38\% of clubs are in a state of negative equity, with debt levels exceeding the value of club assets (Franck, 2014).

It is against this backdrop that financial regulations were implemented across Europe, initiated by UEFA's (Union of European Football Associations) own Financial Fair Play (FFP) regulations. Such regulations provide a means through which to introduce discipline and rationality to European club football finances to help safeguard the stability of European football (UEFA, 2015).

Despite the good intentions of FFP, criticism exists about the regulations, particularly regarding suggestions that financial regulations will have an adverse effect on the competitive balance within European football (Lindholm, 2010; Sass, 2014; Szymanski, 2014). This issue has gained significant attention in the literature to date and yet it still warrants further analysis. Consequently, it is the intention of this study to investigate this line of argument in order to determine if it holds any justification. This study will employ a methodology of three different statistical measures (the Herfindahl Index, Scully-Noll ratio, and standard deviation of points) in an attempt to produce a set of results which can offer an insight into the effects FFP regulations have had on the competitive balance in the English Premier League. The results should also provide insights into the trends in competitive balance in the EPL, facilitating further discussion and analysis on the subject of competitive balance.

The article is organized into five sections. Following this introduction, the theoretical foundations of this study are discussed, before its research design is examined. Next, the study's findings will be presented in detail, while investigating the effects of FFP on competitive balance. Finally, the implications of the conclusions to emerge from this 
research are discussed, as well as some recommendations for future research on the subject.

\section{Theoretical background}

This section will explore the existing body of literature on the subjects of competitive balance and financial fair play in order to provide the foundations upon which this study was conducted. The review will begin with the concept of competitive balance as it is the central theme underpinning this research.

A central element to any sporting contest is the concept of competitive balance; the notion that "competitors must be of approximate equal 'size' if any are to be successful" (Rottenberg, 1956, p. 242). Competitive balance is based upon the premise that sporting contests must contain elements of unpredictability and have an uncertain outcome in order to provide entertainment value for spectators (Humphreys, 2002; Késenne, 2007). What is being argued, is that in contrast to traditional economic theory, the sport 'product' is an indivisible, joint-production between the participating teams within a particular league, dependent upon the cooperation and input of every team (Morrow, 2003; Goossens, 2006; Lee and Fort, 2012). Whereas in business the ideal is to achieve a monopolistic position over the competition (as far as the law permits), in sport "pure monopoly is a disaster" because sports teams need opponents of comparable strength to compete against (Neale, 1964, p. 2).

Competitive balance is a topic that has stirred on-going debates within academia regarding its relation with league organisation and club focus. The former has been explored through the study of potential factors of influence, such as gate and TV revenue sharing (Feess and Stähler, 2009; Grossmann et al., 2010), talent distribution (Kesenne, 2006; Winfree and Fort, 2012), salary caps (Dietl et al., 2011a), promotion - relegation system (Andreff, 2011), investment regulations and taxes (Brandes and Franck, 2007; Dietl et al., 2010), number of opponents, and participation in international competitions (Pawlowski et al., 2010). The relations developed both among these factors and between them and competitive balance have attracted contradicting views, while their effects have also been linked with the 
discussion on the profit versus win maximisation focus of each club (Dietl et al., 2009; 2011b; Madden, 2015).

As a result, measuring competitive balance is also considered an area of disagreement amongst academics. A number of methods for measuring competitive balance within sports leagues have been proposed, varying based on the nature and rules of the league (closed or open, introduction of taxes, revenue sharing, see Brandes and Franck, 2006; 2007), the rules of game (possibility of a draw, see Michie and Oughton, 2004) and the talent distribution rules (open or closed market, salary caps see Szymanski and Kuypers, 2000) of the league. Among the many measures of competitive balance are; the Herfindahl Index of Competitive Balance (Michie and Oughton, 2004; Pawlowski et al., 2010), standard deviation of points (Koning, 2000; Szymanski and Kuypers, 2000), and the Scully-Noll ratio (Cain and Haddock, 2006; Lee and Fort, 2012), all of which will be discussed in the methodology section of this study.

While a clear and unanimously accepted answer to the on-going debates surrounding competitive balance has yet to be found, what is evident through the literature, is that the dynamics of competition in club football have now created an environment in which financial resources are increasingly more important as a competitive driver (Franck, 2010). Wealth is the currency with which playing and managerial talent is purchased, therefore financial resources have become an integral antecedent to success, suggesting that European club football has developed into a win-maximisation environment, leaving behind the model of profit-maximisation which previously dominated European football, and remains the most popular ownership model in US sports (Wilson et al., 2013; Franck, 2014). It is for this reason that financial resources in club football are commonly mismanaged and misused, spawning a great deal of concern over the future of European club football and its lack of function efficiency focus (Wilson et al., 2013).

The situation is concerning for two primary reasons; firstly, it has created a financially unstable and volatile environment which could ultimately threaten the long-term viability of European club football (Lago et al., 2006; Franck, 2014). In English football alone, between 1962 and 2009 there were 96 recorded cases of insolvency among 79 different clubs, with thirteen clubs facing multiple instances of financial collapse (Beech et al., 2008). Insolvency 
continues to afflict English football with the most high-profile instance involving Leeds United entering administration in 2007. Having mortgaged the club's future income on the gamble of continued qualification to the UEFA Champions League, Leeds United failed to qualify in 2002 and were consequently left with large amounts of unserviceable debt (Morrow, 2003; Grundy, 2004). By the time Leeds United entered administration in 2007, the club was playing football in the third division, with debts having peaked at $£ 120$ million along the way (Buraimo et al., 2006).

Administration is a favoured option among football clubs facing insolvency as it is a process designed to help ailing businesses rather than punish them (Beech et al., 2008; Szymanski, 2012). Administration proceedings grant administrators temporary control of the indebted business in order to restructure the company finances, with the aim of finding a way to repay creditors as fully as possible (Best, 2011). Following an agreeable debt settlement, the business is permitted to restart anew if it remains commercially viable, thus avoiding the need for the total liquidation of the business and all of its assets (Beech, 2010). 22 Football League clubs alone experienced administration between 1999 and 2004, almost a quarter of the 92 clubs that comprise the Football League (Buraimo et al., 2006). Administration allows clubs to write-off or significantly reduce the level of their debts, thus providing a platform from which to start anew without the burden of debt. This inevitably results in the creditors of football clubs being left short-changed, effectively subsidising the irresponsible financial behaviour of clubs without any choice in the matter due to the social and cultural importance of football clubs (Szymanski, 2012). The survival of football clubs is viewed as highly desirable and as such there is a reluctance, particularly among state creditors, to call in overdrafts and overdue bills in recognition of the potential wider social problems that could be triggered (Buraimo et al., 2006; Beech et al., 2008).

Fully cognisant of the special regard in which they are held, football clubs have taken to exploiting their unique positions of power in the knowledge that they are effectively insured against financial failure by the state (Franck, 2014). The expectation of ex post support is a characteristic of soft budget constraints, a concept developed to describe the state support typically received by loss-making firms in socialist economies, but which also applies to most public sector institutions and the banking and finance sectors (Storm and Nielsen, 2012). Such soft budget constraints are also in evidence in European football, contributing to the 
creation of a culture in which clubs believe they are too big, and too important to fail (Preuss et al., 2014). It is currently the case that a substantial number of European football clubs are technically bankrupt, with the EPL less than a year from bankruptcy when evaluated as a 'normal' business (AT Kearney, 2010; Franck, 2014).

The second major concern is the increasing prevalence of 'financial doping', the practice of relying on significant funding from external benefactors in order to cover perpetual losses, thus gaining a financial advantage over the competition (Muller et al., 2012). These external benefactors, or 'sugar daddies', invest enormous amounts of money into clubs and become their owners, typically for the prestige and utility associated with sporting success, and with little or no regard for the financial losses such endeavours require (Lang et al., 2011). It is now the case that over half of Europe's top-division clubs are perpetual loss-makers, spending money they do not have (Beech et al., 2008). The application of the term 'doping' to this context is indicative of clubs' attempts to gain an illegitimate advantage through the artificial manipulation of the natural competitiveness inherent in sport (Schubert and Könecke, 2015). The consequence of this phenomenon has been the negative distortion of competitive balance both within and between European leagues (Schubert and Könecke, 2015). The competitive balance within each of Europe's top five leagues has been declining since the turn of the millennium, coinciding with the huge increases in domestic and Champions League prize money (Curran et al., 2009; Pawlowski et al., 2010; Lee and Fort, 2012). UEFA now distributes as much as $€ 1$ billion per season among the participants of each year's Champions League tournament on a pro-rata basis, but over the last decade half of all Champions League money has been distributed among just ten clubs (Szymanski, 2014). Furthermore, the market value of the smallest teams from each of the top five divisions during the 2006/07 season was far below $€ 50$ million, whereas a number of the most valuable clubs had a market value well in excess of $€ 300$ million (Frick, 2007; Pawlowski et al., 2010). Among Europe's top five leagues only the Spanish League has a lower competitive balance than the EPL, a symptom of the huge financial rewards on offer in English football (Goossens, 2006; Hann et al., 2007; Naghshbandi et al., 2011).

The phenomenon of 'financial doping' developed in response to the increasing financial rewards offered in European football, greatly increasing the incentives for success. The situation that has developed since has seen clubs spending beyond their financial means, 
incurring huge debts as they are locked into an inflationary spiral of ever increasing transfer fees and salaries as they chase sporting success and the financial rewards that result (Hill, 2011). According to Kesenne (2006) and Solberg and Haugen (2010), it is the win-maximising nature of European football clubs that has made clubs irresponsible and profligate in their spending behaviour, as they seek to fulfil their single-minded objectives of sporting success by any means necessary. This destructive 'arms race' (Franck, 2010) that has developed sees clubs risking their long-term financial health in order to achieve short-term sporting success (Storm and Nielsen, 2012; Schubert and Könecke, 2015). In such an environment the sporting competitiveness of a club is not determined by its profitability or financial liquidity, but by its spending power (Franck, 2010; 2014). Beech et al (2008) go so far as to suggest that administration has become a legitimate business tactic for clubs looking to spend their way to sporting success, entirely neglecting the fundamental elements of a profitmaximisation or function efficiency strategy that aim to ensure the financial stability and sustainability of a firm (Wilson et al., 2013).

It is against these rising concerns that UEFA introduced its own Financial Fair Play regulations, designed to regulate the financial behaviour of clubs competing in UEFA club competitions. Whilst there are 734 top-division clubs across Europe, only 235 each season qualify to play in UEFA competitions and as such UEFA's FFP regulations only ever apply to 235 of the 734 top-division clubs each season (Szymanski, 2014). As a result, the EPL, Football League, and numerous other national associations across Europe have since implemented their own variations of financial regulations to ensure that all clubs are obliged to adhere to certain financial standards (Hill, 2011).

UEFA's FFP regulations are intended to: encourage responsible spending, protect the creditors of clubs, and encourage clubs to operate on the basis of their own revenues, all of which contribute to the overarching objective of protecting the long-term viability and sustainability of European club football (UEFA, 2015). These objectives are to be achieved through two mechanisms of the regulations; the no overdue payables rule and the breakeven rule (Peeters and Szymanski, 2013). The no overdue payables rule is designed to protect against the non-payment and delayed payment of liabilities by clubs to their employees, social and tax authorities, and other football clubs. This element of the regulations will bring football clubs in line with standard business practice and serve to 
protect creditors from becoming involuntary investors in clubs (Szymanski, 2014).

Compliance with the break-even rule is also necessary, requiring clubs to balance their expenses and income (UEFA, 2015). Whilst there are some exceptions to this rule (Szymanski, 2014), and a transitional period during which an 'acceptable deviation' is permitted, the break-even rule will eventually require clubs to balance their books completely in order to be admitted into UEFA club competitions. The various other adaptations of financial fair play regulations in place across Europe differ slightly in their specific details but all are derived from UEFA's FFP regulations and are therefore built upon the same legal framework.

Despite the concerns surrounding European football which led to the introduction of financial regulations, and the active involvement of clubs in seeking out these changes (Geey, 2011), financial fair play regulations, and UEFA's FFP regulations in particular, have received a number of criticisms. Critiques have centred around: the legality of FFP regulations (Long, 2012; Peeters and Szymanski, 2013; Szymanski, 2014); the belief that FFP regulations will cause a reduction in the quality of all teams (Drut and Raballand, 2012; Madden, 2012); the belief that FFP regulations will create an unnecessary downward pressure on players' wages (Dietl et al., 2009; Peeters and Szymanski, 2012; Preuss et al., 2014); and the fact that such regulations will prevent the industry from benefiting from substantial injections of external financing (Madden, 2012; Franck, 2014).

However, the criticism that has gained most attention among academics relates to the negative effects that such strict financial regulations could have on competitiveness. The break-even requirement is viewed as being analogous to a relative salary cap, whereby each club is constrained in its spending power by its own market potential, thus making it difficult for smaller clubs to compete (Lindholm, 2010; Sass, 2012). The effect would be to further entrench the existing hierarchy of European club football, strengthening the power of the wealthiest clubs by restraining the smaller clubs (Sass, 2014; Szymanski, 2014). This argument is based upon the premise that spending power provides the true competitive advantage in football, making it "almost impossible to catch-up to the bigger clubs without external funding" (Vopel, 2013, p. 17). Nevertheless, Franck (2014) offers an alternative view, suggesting that FFP restores the incentives for good management and innovation, 
providing a more reliable way to disrupt the established hierarchy. Furthermore, Franck (2014) proposes that limiting clubs to their own market potential will actually serve to reduce the competitive gap between favourites and underdogs by restricting the advantage bigger clubs can gain from benefactor money.

It is the case that European football has always been characterised by a competitive imbalance, with most leagues having been dominated historically by no more than three or four teams (Peeters and Szymanski, 2013). Furthermore, the competitive balance within European football has been in decline ever since the 1990s, affecting both intra-league and inter-league competitiveness (Pawlowski et al., 2010). As of 2012, the number of titles won by the three most successful clubs in each of Europe's top five leagues had risen to $77 \%$, but this is only a modest increase from the figure of 71\% for the period 1971-1991 (Peeters and Szymanski, 2013). The competitive state of European football prior to FFP provided no evidence to suggest a reversal in the negative trend of competitive balance was forthcoming. Thus, whilst the FFP regulations detail no specific objective or intention of addressing the issue of competitive imbalance within European football (Lindholm, 2010), the regulations serve to shake-up the rules and disrupt the status-quo (Franck, 2014). The status-quo was characterised by a disequilibrium in competition and a volatile financial situation, and FFP serves at least to introduce discipline and rationality to European football, and shift the focus of competition from external financial injections to good management and efficiency. This should ultimately narrow the avenues for gaining instant success through cash injections, encouraging more organic investment and growth (Geey, 2011).

Despite the conjecture on this subject, no analysis has yet been carried out to assess the level of competitive balance in the EPL since the implementation of financial regulations. Therefore, it is difficult to reliably evaluate what impact, if any, such regulations have had on competitive balance. In the absence of any evidence it is difficult to assess the credibility of such conjecture, and thus improper to pass any judgement on the potential impacts or effectiveness of FFP regulations. For this reason, the present study will carry out an analysis of the competitive balance in the EPL over the past 21 seasons, in order to deliver a clearer understanding of the competitive balance trends and effects of the FFP regulations over recent years. 


\section{Methodology}

As the review of the literature surrounding FFP regulations in European football has highlighted, there exist a number of arguments suggesting that the introduction of these regulations will reduce the competitive balance in European club football, and in particular, the Premier League. It is therefore the intention of this research to investigate the value of such claims through an analysis of the relevant data in order to either substantiate or reject the theory that FFP has a negative effect on competitive balance in the Premier League.

Competitive balance is a measure of the relative performance of every team within a particular sports league, used to give an indication of how evenly-matched the teams are (Goossens, 2006). There is no one single measure of competitive balance, with the appropriate measures varying depending on the rules, structure and format of the sporting competition in question. This research will be conducted on the basis of the points totals of each team at the end of every season as this metric provides the most accurate indication of overall performance (Evans, 2014). The Premier League awards teams one point for a drawn match and three points for a victory (Premier League, 2015), therefore any metric used here must incorporate both wins and draws to be considered a valid measure of overall performance. Equally, league position is determined by the number of points each team collects over the duration of the season, with the team with the highest points total winning the league (Premier League, 2015), thus it is logical to assess performance based upon the same metric.

Nevertheless, points are not the only metric that can be used to assess relative performance; win percentage, goals scored, goals conceded, goal difference and league position can all be employed as proxies for performance. Win percentage is commonly used to assess performance in North American sports, as they typically function on a winloss basis, playing out every game to a victory to avoid tied games (see Scully, 1989; Quirk and Fort, 1992). The number of goals scored and/or conceded by a team can provide some useful information about the relative performance of a team, but as a standalone indicator of performance it can be misleading. Match results, and therefore points, are not determined by the total number of goals scored and conceded but instead by the number 
of goals scored relative to the opposition in each given match, thus scoring lots of goals or conceding few does not guarantee victory or the collection of any points. Lastly, the use of league position as an indicator of performance can also be misrepresentative, as league position does not provide any indication of the relative points difference between each position. It is the points-based system that best encapsulates the overall and relative performance of every team within a league of this nature (Evans, 2014).

The Herfindahl Index of Competitive Balance will be employed as the primary measure of competitive balance in this study, but in order to ensure robustness the results will be cross-examined with two other measures of competitive balance: standard deviation of points, and the Scully-Noll ratio. The Herfindahl Index is a measure developed to assess the inequalities that exist between all of the firms in a given industry, and it has since been adapted as a means by which to analyse the competitiveness of sports leagues (Michie and Oughton, 2004; Brandes and Franck, 2006). When analysing a sports league of the format of the Premier League, the market share variable is substituted for each club's share of points, as points are the currency with which performance and success are measured in the EPL.

Regarding the other two measures to be employed, both are based on standard deviation calculations. The standard deviation of points measure provides a statistical measure of the distribution of points among each club relative to the average points total for the league (Goossens, 2006). The Scully-Noll ratio builds on the results produced by the standard deviation of points analysis by comparing the actual standard deviation value for each season with an idealised standard deviation figure based on a theoretical league that is equally balanced (Noll, 1988; Scully, 1989; Lee and Fort, 2005).

Competitive balance values will be produced for each of the past 21 Premier League seasons, starting with the 1995/96 season, through to the $2015 / 16$ season, using each of the three methods listed above. The 1995/96 season was chosen as the starting point of the data set because it was the first season to feature just twenty teams, in line with the format of the league at present. Both the Herfindahl Index and standard deviation calculations are a function of the number of teams in a league, therefore it is important that the league format remains consistent throughout the dataset to ensure the reliability of the results (Michie and Oughton, 2004). With a representative and comparable statistic 
for each season it will then be possible to compare the results over the 21 -year period to identify any trends that may have occurred. In particular, a comparison of data before and after the introduction of FFP in 2011.

The results of this analysis will also be complimented by a measure of the range between the total number of points for the top-ranked team and the bottom-ranked team, providing a simple indication of the spread of points in the league. Whilst the range measure takes no account of the concentration of data between the highest and lowest data points and therefore should not be employed in isolation, it does provide an alternative indication of competitive balance, which can be utilised alongside the three aforementioned primary measures to provide a more representative overall impression of competitive balance (see Appendix C).

Financial fair play regulations have only been in effect since the start of the $2011 / 12$ season and therefore there is only five seasons worth of data to analyse. The introduction of FFP has been staggered over a number of seasons so as to assist clubs with the transition to the new regulations. Consequently, there has been limited time for the FFP regulations to have an effect on the competitive balance within the Premier League, be it positively or negatively. Since the introduction of FFP regulations in 2011 all clubs will have had to begin the process of bringing their club finances in line with the new regulations, yet acceptable levels of deviation from the break-even requirement are still permitted, and thus the full effects of FFP may not be truly felt until the acceptable deviation level is lowered tozero.

Equally, the unpredictable nature of sport, and particularly of European club football means that there are naturally fluctuations in club performance levels every year (Buraimo et al., 2007), and therefore it could be difficult to differentiate between the natural fluctuations in competitive balance and any changes that may have occurred due to the introduction of FFP. Even if the results were to suggest a noticeable shift in competitive balance has occurred since the introduction of FFP, it will be difficult to attribute this change directly and solely to FFP with full confidence as there are many other factors that can potentially impact upon competitive balance. Nevertheless, examining the trends in competitive balance and any effects the FFP regulations might have had in the PL can provide valuable insights for the future of European club football 
and its management.

\section{Findings and discussion}

After data from the $21 \mathrm{PL}$ seasons were collected from the official website (see Appendix A - Premier League, 2016a), they were analysed using the Herfindahl Index, Scully-Noll ratio and Standard Deviation of points, to provide measures of competitive balance (see Appendix B). Based upon the share of total points each club achieves relative to the rest of the competition, the Herfindahl Index produces a figure to illustrate the depth of inequality that exists between the clubs of a league. In a twenty-team league such as the EPL, the Herfindhal Index results will fall within the range of 0.05 to 0.07 , where 0.05 represents a perfectly balanced league and 0.07 represents a perfectly unbalanced league (Michie and Oughton, 2004).

Initial observations of the minimum, maximum and mean points values (Figure 1) and the points differentials (Figure 2) highlight the varied and unpredictable nature of football (Buraimo et al., 2007). As can be seen in the data, even though the EPL will always develop into a natural hierarchy, the absolute points totals can vary significantly between individual seasons. This serves to highlight that comparisons made on an individual season basis can be limited, with long-term trends proving much more revealing and representative.

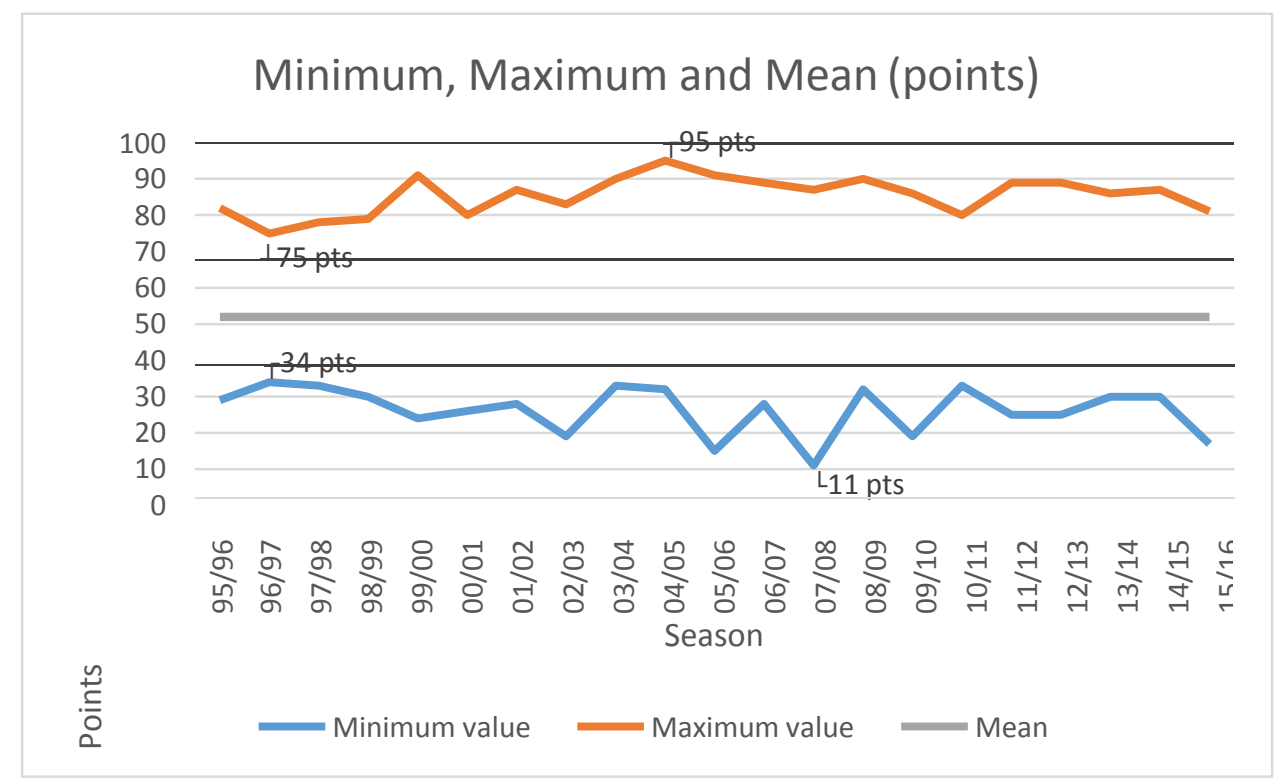

Figure 1: Minimum, maximum and mean points values 


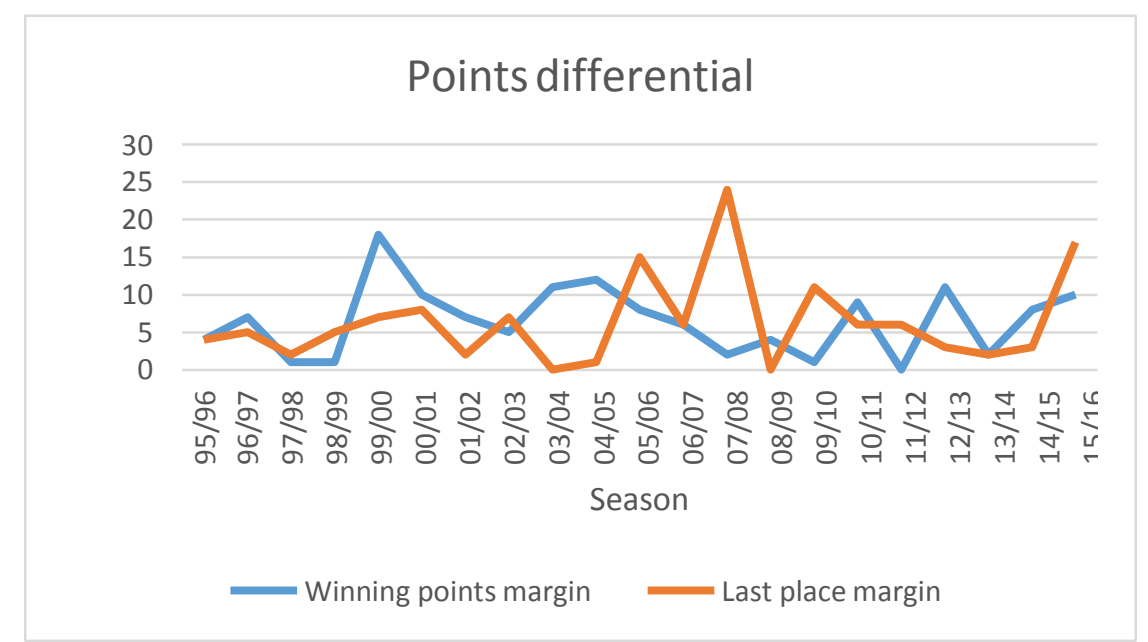

Figure 2: Points differentials (winning margin and last place margin)

This becomes clear when examining the range calculations, which measure the point differential between first position and twentieth (last) position. Figure 3 shows how varied the range can be from season to season, with a low of 41 points and a high of 76 points over the previous 21 seasons. It is interesting to note that the 76-point differential, achieved in $2005 / 06$ and $2007 / 08$, is larger than the winning points total in 1996/97 (75 points), and larger than the points totals of second-placed teams on four occasions. In light of the fact that Sunderland FC finished bottom of the league in 2005/06 and had the league's lowest market value $(€ 36,550,000)$, while Chelsea FC won the league with the highest market value $(€ 366,075,000)$, the 76-point differential between the two teams appears more understandable (Frick, 2007). The fact that Watford FC finished bottom of the league the following season with a market value of just $€ 20,800,000$ and Chelsea FC ( $€ 404,775,000)$ finished second highlights the sheer importance of financial strength as a driver of competition (Frick, 2007; Franck, 2010). When wealth is such a key factor in sporting success it encourages risky and irresponsible financial behaviour as clubs seek any means by which to win (Franck and Lang, 2013). The over-inflated importance and misuse of financial resources are the two primary areas that FFP regulations are aimed at addressing (Muller et al., 2012). 


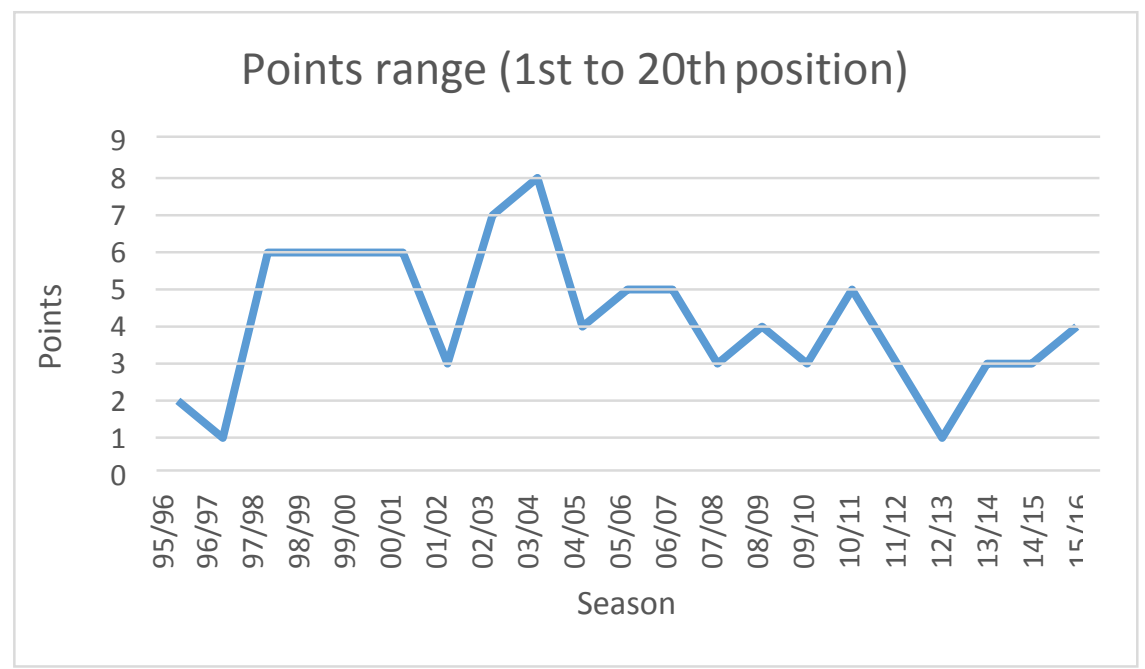

Figure 3: Points range (1st to 20th position)

When the range is analysed using a three-season moving average (see Figure 4) trends emerge more clearly as the data spikes are smoothed out. Figure 4 illustrates a clear upward trend in the range between 1996/97 and 2005/06, increasing from 41 points in 1996/97 to 76 points in 2005/06. From the peak of 2005/06 there has been more of a downward trend in the range, although this trend is much less smooth - a result of considerable fluctuations every season between 2005/06 and 2011/12. A downward trend in range is desirable as it provides evidence of a closer concentration of the data, although in isolation it is an inadequate measure of competitive balance. However, the range results, combined with the maximum and minimum points totals, can help to allay concerns that FFP will reduce the quality of the EPL overall (Madden, 2012). The average winning points total over the five seasons since the introduction of FFP (86.4 points) has been marginally higher than the average for the entire data set ( 85.5 points), whilst the average range and bottom-ranked points totals for the past five seasons have also been within two points of the 21-season average (1.85 points and 0.93 points respectively). The limited change in these numbers would indicate that there has been no significant change in the overall quality of the EPL, counter to concerns expressed by Madden (2012). 


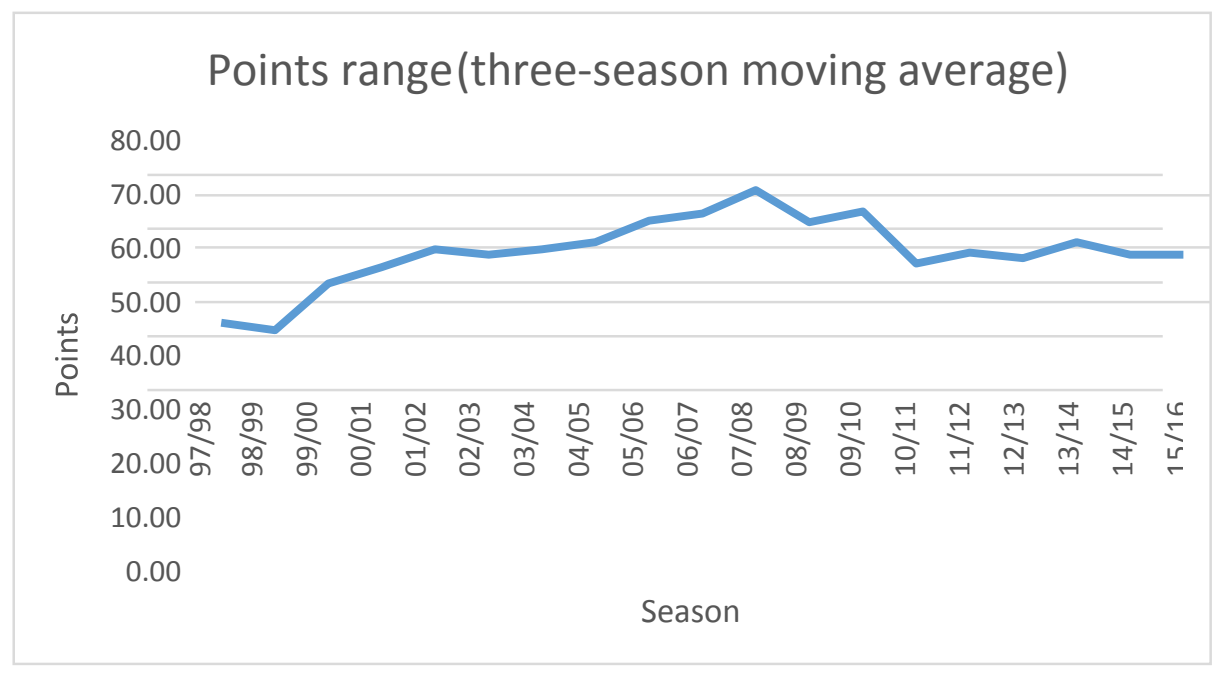

Figure 4: Points range (three-season moving average)

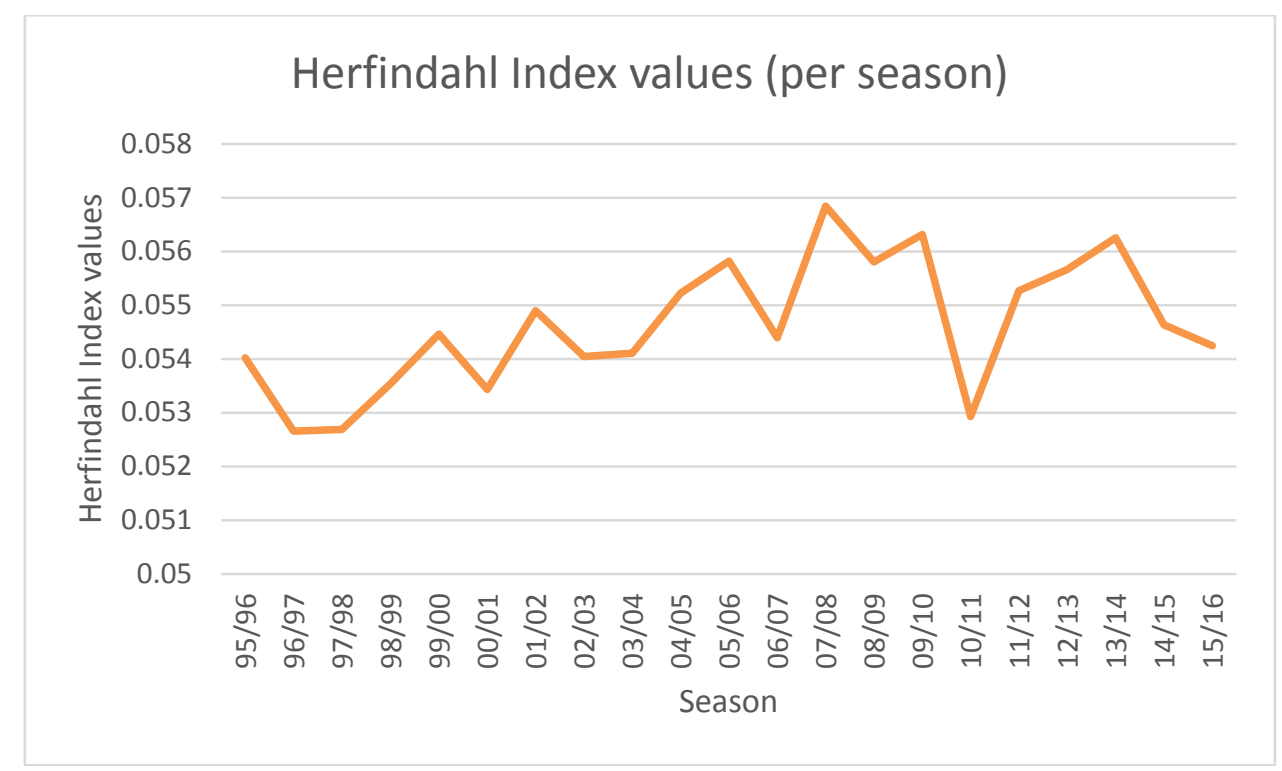

Figure 5: Herfindahl Index values

The Herfindahl Index results (see Figure 5) suggest there has been a general decline in competitive balance in the EPL since 1995/96, supporting existing research in this field (Michie and Oughton, 2004; Goossens, 2006; Pawlowski et al., 2010). The Herfindahl Index results are supported by a set of analogous results from both the Scully-Noll ratio and the standard deviation analysis (see Appendix D). From 1996/97 through to 2007/08 there is an undeniable upward trend in Herfindahl Index values, with the results increasing from 
0.052659 (the lowest data point) to 0.056842 (the highest data point). This negative trend in competitive balance can at least in part be attributed to the sizable financial disparities that developed between clubs during this period, caused by vast increases in prize money being awarded for sporting success, as Drut and Raballand (2012) and Lee and Fort (2012) argue. The phenomenon of money coming to money and the absence of any true revenue sharing mechanisms ensures that the wealthy and successful clubs earn a disproportionately large share of income, to the detriment of the remaining majority of clubs (Szymanski and Kesenne, 2004; Lee and Fort, 2012). Pawlowski et al (2010) focused specifically on the effect that increases in UEFA Champions League payments had on competitive balance, producing a range of results that support the suggestion that the increase in financial rewards has led to a decrease in competitive balance in the EPL (and elsewhere in Europe). Goossens' (2006) results also highlight the central role of Champions League payments in triggering a decline in competitive balance and creating a wealthy elite of clubs at the top of the league. Indeed, in three consecutive seasons between 2006/07 and 2008/09 the points differential between fourth and fifth position was eight points, eleven points and nine points respectively. Furthermore, over the tenyear period from 1998/99 to 2007/08 only seven different teams finished in one of the top four league positions, and $85 \%$ of the time it was the same four teams that occupied these four positions (Curran et al., 2009). As Michie and Oughton (2004) and Vopel (2013) argue, this sign of 'domination' suggests that the EPL is functioning as an oligopoly that is difficult to challenge and almost impossible to sustain a challenge against, mainly due to the revenue rewarding nature of finishing in the top positions and subsequently qualifying for participation in European competitions (Pawlowski et al., 2012).

After the peak value in $2007 / 08$ the trend is more towards a general decline in Herfindahl Index values, although this incorporates four seasons of decline and four seasons of growth. The results show a fluctuation in the data almost every season, with a constant pattern of an increase in competitive balance followed by a decrease in competitive balance in the subsequent season, resulting in the high frequency of data spikes in Figure 5. The major standout is the large, negative spike in 2010/11 - a figure of 0.052931 - which was a decline of 0.003387 from the previous year, and 0.002341 lower than the value for the season that followed. 0.052931 is the third-lowest value in the data set, and the lowest 
figure since 1997/98, making it somewhat of an anomaly, particularly considering the seasonal values had not dropped below 0.054 since 2000/01, and have not done so since.

A closer observation of the $2010 / 11$ data illustrates why the Herfindahl Index value is so low (relative to the dataset). The 2010/11 season produced the third-lowest range figure in the dataset; this can be attributed to having the second-highest score for the bottomranked team (33 points), and a relatively low winning points tally of 80 , making the points differential just 47 points - twenty points fewer than the range for the previous season. Additionally, the mean number of points for the 2010/11 season was 51.45; eight clubs came within six points of the mean ( $7^{\text {th }}$ to $14^{\text {th }}$ position), and were separated by just eight points. Furthermore, the five clubs in positions fifteen through nineteen were separated by just four points, and together these thirteen clubs were separated by a total of just fifteen points - that is, $65 \%$ of the league's clubs separated by just $32 \%$ of the total points range. This tight grouping of clubs has the effect of negating the impact of some of the larger points differentials present between certain clubs elsewhere in the league, such as the winning margin of nine points, the margin of six points between $4^{\text {th }}$ and $5^{\text {th }}$ position and $19^{\text {th }}$ and $20^{\text {th }}$ position, and the five-point differential between $7^{\text {th }}$ and $8^{\text {th }}$ position (see Figure 6). That the league is incredibly close from $7^{\text {th }}$ position through to $19^{\text {th }}$ is indicative of the relative financial parity that exists below the exclusive group of 'rich' clubs at the top of the table, which secure an additional income from participating in European competitions (Pawlowski et al., 2010; Vopel, 2013). It is only at the summit of the table where the larger point-gaps emerge as the larger disparities in wealth are reflected in sporting performance, with further divisions between the rich and the mega-rich (Lang et al., 2011). Thus, whilst it is clear from the data that the 2010/11 season was relatively competitive (particularly in mid-table), the fact that larger point-gaps were present elsewhere in the league cannot be overlooked, and should be considered when viewing the Herfindahl Index value of 0.052931 . 


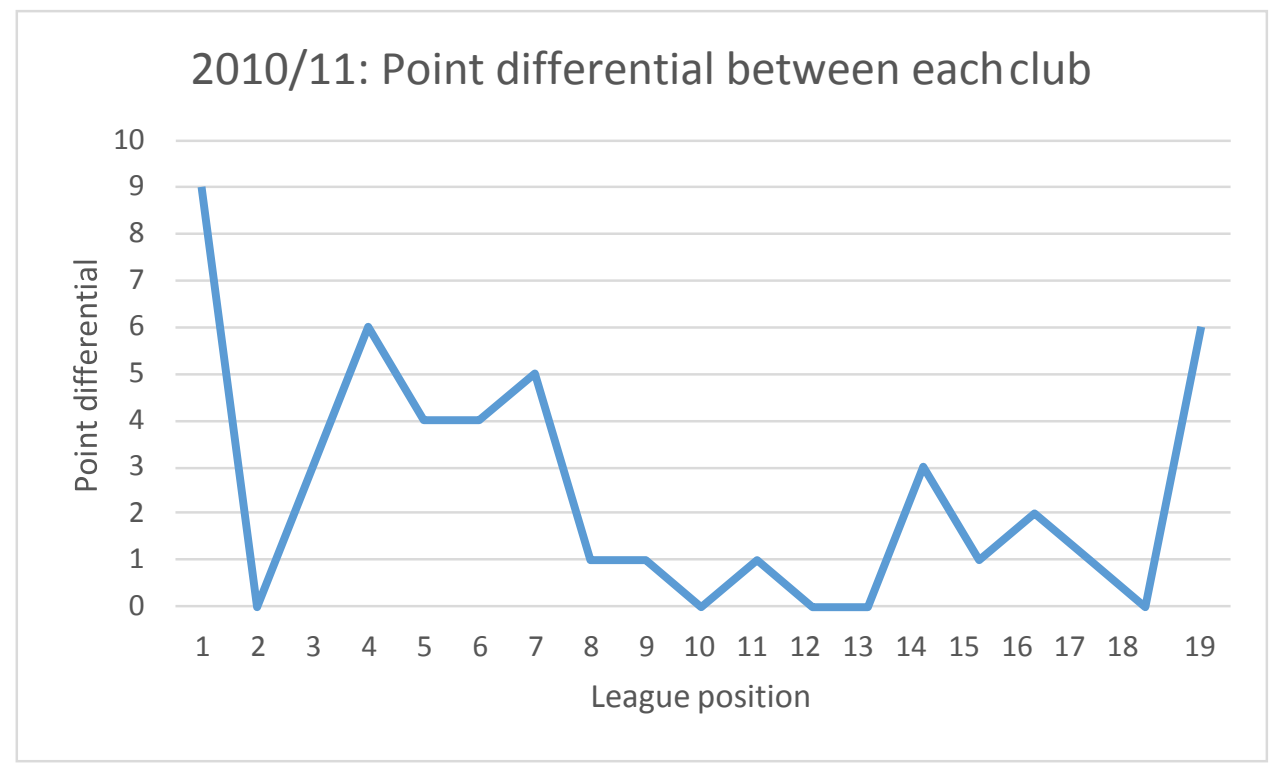

Figure 6: Point differential between each club (2010/11)

Interestingly, this season of relatively high balance in competition was directly preceded by the peak period of imbalance, during which the Premier League experienced three of the five highest Herfindahl Index values in consecutive seasons. Additionally, the 2010/11 season was the final season before the introduction of FFP regulations, thus it is possible that at least some of the increase in competitive balance can be attributed to readjustments made by clubs in preparation for the new regulations.

UEFA's FFP regulations were introduced at the start of the 2011/12 season, with the first assessment of the break-even requirement occurring after the 2012/13 season (UEFA, 2010). Under the current format the break-even requirement limits acceptable losses to $€ 45$ million for the first monitoring period ${ }^{1}$, $€ 45$ million for the second monitoring period, and $€ 30$ million for the following three monitoring periods (UEFA, 2010). Whilst the Herfindahl Index values increased year-on-year during the first three seasons of FFP, the two subsequent seasons saw successive declines in Herfindahl Index values. The first monitoring period (covering the 2011/12 and 2012/13 seasons) coincided with a marginal decrease in competitive balance suggesting that the $€ 45$ million acceptable loss was too lenient to have much of an impact upon spending. The following season competitive balance decreased again, but more significantly this time, potentially a result of clubs maximising the remainder

\footnotetext{
${ }^{1}$ UEFA monitoring periods fall at the end of every season and comprise the three seasons prior to the monitoring period date. The first monitoring period assesses just the first two seasons (2011/12 and 2012/13).
} 
of their $€ 45$ million allowance during the final year of the monitoring period. Following the first two monitoring periods the acceptable loss was reduced to $€ 30$ million, with the more stringent limitations coinciding with an increase in the competitive balance in the EPL. The tightening of UEFA's regulations also coincided with the introduction of the EPL's own financial fair play regulations, which limit clubs to aggregate losses of $£ 105$ million for every three-year period (Premier League, 2013).

The 2014/15 and 2015/16 seasons saw a year-on-year increase in competitive balance only the second occasion during the selected time period that the competitive balance values increased for two consecutive seasons. Additionally, the 2015/16 season produced the lowest Herfindahl Index score since 2003/04 (2010/11 anomaly aside), and returned to a score almost level with the first data point in 1995/96. It is worth noting that the Herfindahl Index value for 2015/16 has actually been distorted upwards by the large differentials at the top and bottom of the league (see Figure 7), without which the league would have been considered even more competitive than the 0.054244 Herfindahl Index value suggests. These results indicate that the FFP rules may be having some effect on the competitive balance within the Premier League, contributing to an increase in equality and competitiveness.

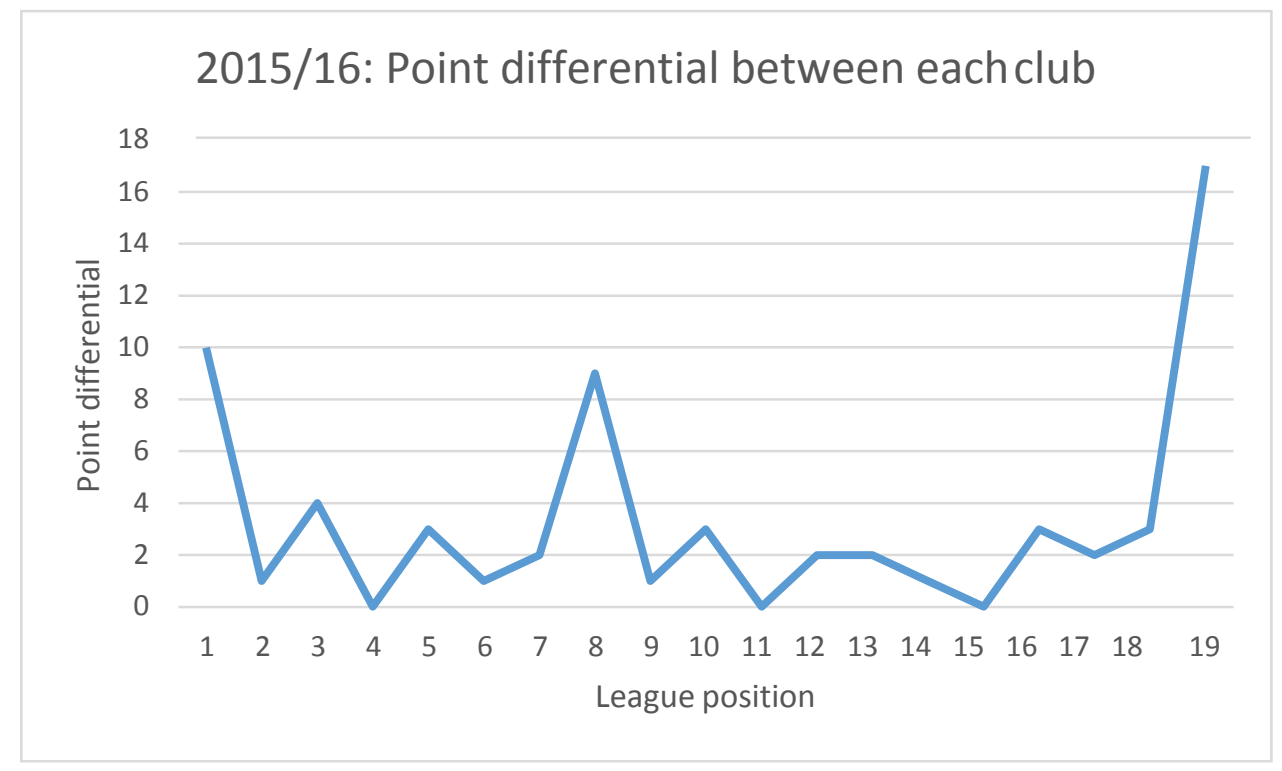

Figure 7: Point differential between each club (2015/16) 
The defining feature of the $2015 / 16$ season was the overall victory by Leicester City - only the sixth team to win the league in the EPL era, and the first first-time winner of the topdivision since Nottingham Forest's victory in 1977/78. According to EPL data (Premier League, 2016b) 47 different teams have appeared in the EPL since 1992 and yet only six teams have been able to win the league title. Furthermore, twenty of the 24 EPL titles have been shared among just three clubs (Manchester United, Chelsea, Arsenal) demonstrating just how difficult it has traditionally been to break the stranglehold of the wealthy clubs at the top. Indeed, prior to the $2015 / 16$ season, only six different clubs had featured in the topfour of the EPL over the previous decade, with one of the three aforementioned clubs missing out on a spot in the top-four on just two occasions. However, more promisingly for the competitive balance of the EPL, the last four seasons have produced four different title winners and seven different teams have finished in the top-four.

The fact that Leicester City had finished the previous season in 14th position with just 41 points illustrates that upward mobility is becoming increasingly possible with clubs no longer frozen into the long-established hierarchy (Michie and Oughton, 2004). According to Curran et al. (2009), this change has been assisted by the continual increase in the value of broadcasting rights income in the EPL, making all clubs wealthier and reducing the relative disparity in income that has been an ever-present feature of the league in recent years. The 2013 domestic broadcasting rights deal worth $£ 3.018$ billion made every EPL club much wealthier, while at the beginning of the $2016 / 17$ season the new $£ 5.136$ billion deal will become active, reducing further the disparities in income between clubs (BBC, 2015). As of 2014/15, seventeen EPL clubs were among the richest 30 clubs in world football (expected to include all twenty clubs after income from the new deal) and this has served to reduce the relative importance of absolute wealth (Deloitte, 2016). Whereas previously there existed a clear divide between rich and poor clubs in the EPL (see Michie and Oughton, 2004), now all clubs are relatively wealthy, vastly improving their individual competitive ability.

Furthermore, it stands to reason that given the declining advantage that can be derived from wealth, other factors will assume more importance and act as competitive drivers in place of wealth. The emphasis will now be shifted towards efficiency, innovation and good management as they provide areas from which clubs can differentiate themselves and develop a competitive advantage (Wilson et al., 2013; Franck, 2014). These areas provide 
means of natural growth and create a level platform from which all clubs compete with access to the same resources (Geey, 2011). The previous platform of competition, which prized financial wealth above all else, and placed no restrictions on the means of procuring financial resources, created an environment within which a select few clubs could create an hegemony and almost guarantee the permanence of the established order, thus perpetuating the win-maximisation environment that had been established (Lang et al., 2011). Financial fair play regulations aim to ensure that it is no longer possible to maintain a position of dominance through artificial means, only through sporting merit.

Concerns that the introduction of financial restrictions of this nature would inevitably have the effect of freezing clubs into the existing hierarchy based upon their current financial strength were understandable as this seemed unavoidable at the onset of FFP (Peeters and Szymanski, 2013; Sass, 2014). Nevertheless, the new competitive environment should make it possible and more realistic for clubs to challenge the existing hierarchy and achieve growth as success will no longer be so reliant upon the financial resources at a club's disposal.

The results presented in this section provide an insight into the changing nature of the competitive balance in the EPL over the previous two decades. Previous literature and the results produced here both highlight a negative trend in competitive balance in the EPL (see Lee and Fort, 2012), although the more recent results presented above indicate a potential break to this trend has begun to develop since 2011. If the trend continues as the literature and results presented suggest is possible, it could see the EPL entering a new and unexplored competitive balance era, transitioning away from the 'Modern Period' of reduced competitive balance examined by Lee and Fort (2012) into a new era of greater competition. The discussion above has drawn on these results to present some arguments that suggest the anticipated negative impact of FFP regulations on competitive balance (see Lindholm, 2010; Sass, 2014; Szymanski, 2014) has not materialised. At this point in time the criticisms of FFP appear unwarranted, with some indications from the results suggesting that FFP regulations are potentially having a positive effect on the competitive balance in the EPL.

\section{Conclusion}


This study has undertaken an assessment of the effects of financial fair play regulations on the EPL. Literature on the topic highlights a number of criticisms that have been levelled at FFP regulations, which revolve around the legality and necessity of the regulations, and the potential side-effects such regulations could cause. In light of criticisms that FFP regulations would have adverse effects on the EPL, particularly regarding the competitive balance, this study took the opportunity to further investigate these arguments. With limited empirical data available at the time, the criticisms of FFP derived from theories, hypotheses, and extrapolations from similar situations in other sport and business contexts. However, with five seasons having now passed since the introduction of FFP there exists more data upon which an indicative analysis can now be based.

The primary concern regarding FFP is that the regulations will cause a decline in competitive balance in the EPL (and elsewhere). This is based upon the premise that the regulations will, in effect, freeze the existing hierarchy and therefore preserve the status of the wealthy elite of clubs at the top of the league (Sass, 2014; Szymanski, 2014). 'Freezing' would occur because smaller clubs would no longer have access to external sources of financing, making it almost impossible to compete with bigger clubs in an environment where spending power is fundamental to success (Vopel, 2013). Critics argue that FFP would entrench the existing order, disproportionately benefiting the select few clubs that were able to take advantage of the prior lack of financial regulation in football.

The results from this study help to illustrate the sheer imbalance that characterised European football prior to FFP regulations. The trend shows a gradual decrease in the competitive balance in the EPL over the decade preceding the introduction of FFP, with the literature highlighting these results as part of a long-term decline in competitive balance (Goossens, 2006). The EPL, like many European leagues, has been characterised by increasing levels of segregation, division and inequality between its member teams (Michie and Oughton, 2004).

Having analysed data from the previous $21 \mathrm{EPL}$ seasons, the results also suggest that there is little evidence to support the criticisms against FFP. Supportive data of these criticisms would have taken the form of an upward trend in the Herfindahl Index values since the introduction of FFP as this would be indicative of further decreases in competitive balance. However, the results produce no compelling evidence to suggest this has been the case, with 
two seasons of decreasing competitive balance directly after the introduction of FFP, followed by two seasons of increasing competitive balance. The results from the two most recent seasons (2014/15 and 2015/16) suggest that perhaps the opposite is true, and that FFP is actually now having a positive impact on competitive balance by helping to shift the dynamics of competition away from spending power and towards more natural means of competition (Franck, 2014). Whilst the presence of two consecutive seasons of increasing competitive balance for only the second time in the data set is an encouraging sign, there is not currently enough data to fully support this claim, especially considering the fluctuating nature of the results throughout the selected time period. The results do however demonstrate no indication of the adverse effects critics anticipated FFP to have on competitive balance.

However, there are some other elements to the results that could be indicative of an increasingly more competitive league. As the discussion section highlighted, the previous four EPL titles were won by four different teams, an occurrence never previously experienced during the EPL era. Furthermore, Leicester City's EPL victory in 2015/16 made it the sixth club to win the league title in the EPL era, and the seventh different club to qualify for the top-four positions in the previous four seasons. Considering that only six different clubs qualified for the top-four positions between 2005/06 and 2014/15, and the previous stranglehold of a select few clubs over title success, this data hints at potential early shifts in the dynamics of EPL competition. If this hypothesis is to be true then the introduction of FFP regulations might even be considered the break point to a new, fifth era of competition, characterised by an improved competitive balance in the EPL (Lee and Fort, 2012).

In light of these results, the regulations appear to be a positive and much-needed initiative for the EPL. Financial fair play regulations as a whole were designed with well-intentioned objectives and in order to facilitate positive change throughout European football, and as such they are now an important and fundamental element of modern-day football (Franck, 2014). The most crucial issue for European football is the sustenance, and first, recovery, of financial balance, an issue which outweighs any desire for competitive balance (Andreff, 2011). Thus, even if FFP initiatives had the effect of further increasing competitive imbalance, the need for stability and corrective action amidst the worsening financial plight of European football necessitated an intervention such as FFP. Besides, it is unclear whether 
the imbalance and inequality that was evident during the first decade of the 21st century could be increased much further, as the EPL in particular was highly imbalanced and segregated (Curran et al., 2009; Pawlowski et al., 2010). Interestingly, the chance that UEFA's FFP and other financial fair play regulations could in fact be contributing to increases in competitive balance would be a huge positive for regulations that do not state such explicit aims (Lindholm, 2010).

The discussion presented throughout has purposely been written in a tentative manner due to the limitations that exist with this study. The use of the Herfindahl Index (and the standard deviation of points and Scully-Noll ratio) acts as a proxy for competitive balance, and because competitive balance is merely a concept and therefore cannot be measured directly, the results presented should not be treated as being a fully accurate representation of competitive balance. It follows that the conceptual nature of competitive balance means there exist a number of viable methods from which to assess it, all of which could potentially produce varying results and lead to differing conclusions. It is also the case that FFP regulations have only been active for five seasons, with none of the regulations yet requiring clubs to fully break even. As a result, the full effects of the regulations will likely not be felt until such time as losses are no longer permitted. Additionally, the shortage of available data means that any conclusions are limited in scope and can only potentially indicate the changing financial environment that lies ahead. These indications, however, suggest that FFP might in fact have a greater influence in the EPL that could lead to potentially significant managerial implications, beyond what was originally intended.

New data will continue to become available every season and the regulations will progressively alter the financial environment in football, thus it is important that research continue to be conducted in this area, investigating the effects of FFP and the trends in competitive balance. This study confined its attention to the EPL, but it would be instructive to be able to compare the results from different leagues across Europe to determine the effects FFP regulations are having there. Significant differences exist between many of Europe's football leagues and therefore FFP regulations could potentially affect individual leagues in very different ways. These potential differences might be significant, considering that the individual FFP regulations adopted by each national association are by no means uniform across Europe. Therefore, it is important that more research is conducted in this 
area to discover the impact of FFP throughout Europe.

There is evidently need for further research on this important area, that can build on the positive indications and insights provided by this study. If FFP regulations can achieve the aim of improving the financial health of European football, while assisting in increasing the competitive balance of a league, then their influence on European club football might be of a greater significance than originally expected. As Wilson's et al. (2013) study suggested, clubs have moved away from the stock-market model of ownership popular during the 1990s, which centred around objectives of profit maximisation, towards a model of foreign ownership where the prioritises are the maximisation of sporting success (utility). This pivot towards clubs being viewed as utilities for rich benefactors or 'sugar daddies' was in large part the cause of the financial problems that beset English football prior to the introduction of FFP. FFP was designed to restrict the influence of benefactor money in football and therefore the utility maximisation model is likely to become much less viable. Wilson et al. (2013) indicate that the stock market ownership model, and indeed, profit maximisation objectives in general, contribute towards greater efficiency, a quality that is likely to become much more important under the auspices of financial fair play. Therefore, FFP is likely to encourage clubs to develop more of a balance between utility maximisation and profit maximisation, potentially inspiring new and innovative business models as a means of regaining a competitive advantage over the competition, or as Franck (2014) suggests, it should result in an increase of good management practice, a virtue often missing from modern club football. 


\section{Reference List}

Andreff, W. (2011), 'Some comparative economics of the organization of sports: competition and regulation in north American vs. European professional team sports Leagues', The European Journal of Comparative Economics, 8(1), 3-27

AT Kearney, (2010), 'Is European Football Too Popular to Fail?', A.T.Kearney EU Football Sustainability Study, 1-8.

BBC (2015), Premier league TV rights: Sky and BT pay $£ 5.1 \mathrm{bn}$ for live games [viewed 10 February 2016]. Available from:http://www.bbc.co.uk/sport/football/31357409 Beech, J. (2010), 'Finance in the football industry', In: Hamil, S. and S. Chadwick, eds. Managing football: An international perspective. Amsterdam: Elsevier/ButterworthHeinemann, pp.119-150

Beech, J., Horsman, S. and Magraw., J. (2008), 'The circumstances in which English football clubs become insolvent', CIBS working paper series, 4, 1-20

Best, S. (2011), 'Sporting sanctions as symbolic violence: an evaluation of how the Football League communicates with fans who challenge the legitimacy of the sporting sanctions policy', Soccer \& Society, 12(5), 664-676

Brandes, L. and Franck, E. (2006), 'How Fans may Improve Competitive Balance-An empirical analysis of the German Bundesliga', Universität Zürich Working Paper, 41, 1-26.

Brandes, L. and Franck, E. (2007) 'Who made who? An empirical analysis of competitive balance in European soccer leagues', Eastern Economic Journal, 33(3), 379-403.

Buraimo, B., Forrest, D. and Simmons, R. (2007), 'Outcome uncertainty measures: how closely do they predict a close game?', In: Albert, J. and R. H. Koning, eds. Statistical thinking in sports, Boca Raton, FL: Chapman \& Hall/CRC, pp.167-178.

Buraimo, B., Simmons, R. and Szymanski, S. (2006), 'English football', Journal of Sports Economics, 7(1), 29-46.

Curran, J., Jennings, I. and Sedgwick, J. (2009), "Competitive balance' in the top level of 
English football, 1948-2008: An absent principle and a forgotten ideal', The International Journal of the History of Sport, 26(11), 1735-1747.

Deloitte (2016), Deloitte football money league [viewed 26 June 2016], Available from: http://www2.deloitte.com/uk/en/pages/sports-business-group/articles/deloitte-footballmoney-league.html

Dietl, H., Franck, E. and Lang, M. (2009), 'Overinvestment in team sports leagues: Acontest theory model', Scottish Journal of Political Economy, 55, 353-368.

Dietl, H. M., Lang, M. and Werner, S. (2010), 'The effect of luxury taxes on competitive balance, club profits, and social welfare in sports leagues', International Journal of Sport Finance, 5(1), 41-51.

Dietl, H. M., Lang, M. and Rathke, A. (2011a), 'The combined effect of salary restrictions and revenue sharing in sports leagues', Economic Inquiry, 49(2), 447-463.

Dietl, H. M., Grossmann, M. and Lang, M. (2011b), 'Competitive balance and revenue sharing in sports leagues with utility-maximizing teams', Journal of Sports Economics, 12(3), 284-308.

Drut, B. and Raballand, G. (2012), 'Why does financial regulation matter for European professional football clubs?', International Journal of Sport Management and Marketing, $1(1 / 2), 73-88$.

Evans, R. (2014), 'A review of measures of competitive balance in the 'analysis of competitive balance' literature', Birkbeck Sport Business Centre Research Paper Series, 7(2), 1-59.

Feess, E. and Stähler, F. (2009), 'Revenue sharing in professional sports leagues', Scottish Journal of Political Economy, 56(2), 255-265.

Franck, E. (2010), 'Private firm, public corporation or member's association - Governance structures in European football', International Journal of Sport Finance, 5, 108-127.

Franck, E. (2014), 'Financial Fair Play in European Club Football - What is it all about?', UZH Business Working Paper Series, 328, 1-34.

Franck, E. and Lang, M. (2013), 'A Theoretical Analysis of the Influence of Money Injections on Risk Taking in Football Clubs', UZH Business Working Paper Series, 160, 1-29. 
Frick, B. (2007), 'The football players' labor market: empirical evidence from the major European leagues', Scottish Journal of Political Economy, 54(3), 422-446.

Geey, D. (2011), 'Football League Financial Fair Play: Domestic League Regulation', Entertainment and Sports Law Journal, 10, 1-7.

Goossens, K. (2006) Descriptive analysis of competitive balance within and between European football leagues. In IASE Conference, Bochum, Germany.

Grossmann, M., Dietl, H. and Lang, M. (2010), 'Revenue sharing and competitive balance in a dynamic contest model', Review of Industrial Organization, 36(1), 17-36.

Grundy, T. (2004), 'Strategy and financial management in the football industry', Strategic Change, 13(8), 405-422.

Haan, M., Koning, R. and Van Witteloostuijn, A. (2007), The effects of institutional change in European soccer, Mimeo: University of Groningen.

Hill, J. (2011), 'UEFA and the European Union: the green shoots of a new European public space?', In: Niemann, A., B. Garcia and W. Grant, eds, The transformation of European football: Towards the Europeanisation of the national game, Manchester: Distributed in the United States exclusively by Palgrave Macmillan, pp.40-59.

Humphreys, B. (2002), 'Alternative Measures of Competitive Balance in Sports Leagues', Journal of Sports Economics, 3(2), 133-148.

Kesenne, S. (2006), 'The win maximization model reconsidered: Flexible talent supply and efficiency wages', Journal of Sports Economics, 7(4), 416-427.

Kesenne, S. (2007), The economic theory of professional team sports: An analytical treatment, Cheltenham: Edward Elgar Publishing Ltd, Cheltenham.

Koning, R.H. (2000), 'Balance in competition in Dutch soccer', Journal of the Royal Statistical Society: Series D (The Statistician), 49(3), 419-431.

Lang, M., Grossmann, M. and Theiler, P. (2011), 'The sugar daddy's game: How wealthy investors change competition in professional team sports', International Association of Sports Economists, 11(07), 1-23. 
Lago, U., Simmons, R. and Szymanski, S. (2006), 'The Financial Crisis in European football', Journal of Sports Economics, 7(1), 3-12.

Lee, Y. H. and Fort, R. (2012), 'Competitive balance: Time series lessons from the English Premier League', Scottish Journal of Political Economy, 59(3), 266-282.

Lindholm, J. (2010), 'The Problem With Salary Caps Under European Union Law: The Case Against Financial Fair Play', Texas Review of Entertainment and Sports Law, 12 (2), 189-213.

Long, C. (2012), 'Promoting Competition OrPreventing It? A Competition Law Analysis Of Uefa's Financial Fair Play Rules', Marquette Sports Law Review, 23(1), 75-101.

Madden, P. (2012), 'Welfare economics of 'financial fair play' in a sports league with benefactor owners', Journal of Sports Economics, 16(2), 159-184.

Madden, P. (2015), 'Welfare economics of "Financial Fair Play" in a sports league with benefactor owners', Journal of Sports Economics, 16(2), 159-184.

Michie, J. and Oughton, C. (2004), 'Competitive Balance in Football: Trends and Effects', The Sports Nexus Technical Report, 1-38.

Morrow, S. (2003), The people's game? Football, finance, and society, New York: Palgrave Macmillan.

Muller, J., Lammert, J. and Hovemann, G. (2012), 'The Financial Fair Play Regulations of UEFA: An Adequate Concept to Ensure the Long-Term Viability and Sustainability of European Club Football?', International Journal of Sport Finance, 7(2), 117-140.

Naghshbandi, S., Yousefi, B., Etemad, Z. and Moradi, M. (2011), 'The comparison of competitive balance in Football Premier Leagues of England, Germany, Spain, France, Italy and Iran: a case study from 2009-2010 Season', Journal of Human Sport \& Exercise, 6 (4) 673-681.

Neale, W. (1964), 'The peculiar economics of professional sports', Quarterly Journal of Economics, 78, 1-14.

Pawlowski, T., Breuer, C. and Hovemann, A. (2010), 'Top clubs' performance and the competitive situation in European domestic football competitions', Journal of Sports Economics, 11(2), 186-202. 
Peeters, T. and Szymanski, S. (2012), 'Vertical restraints in soccer: Financial Fair Play and the English Premier League', University of Antwerp Research Paper, 2012(28), 1-40.

Peeters, T. and Szymanski, S. (2013), 'Financial Fair Play in European Football', Paper presented at the 58th Panel Meeting of Economic Policy, 1-48.

Premier League (2013), 'The new financial rules agreed by premier league clubs explained', available at: http://www.premierleague.com/en- gb/news/news/2012-13/feb/premierleague-new-financial-rules-explained.html (accessed 1 July 2016).

Premier League (2015), Premier League Handbook Season 2015/16, London: The Football Association Premier League Limited.

Premier League (2016a), 'Tables', available at: https://www.premierleague.com/tables (accessed 5 July 2016)

Premier League (2016b), 'Premier league history, origins \& list of past champions', available at: http://www.premierleague.com/history (accessed 5 July 2016).

Preuss, H., Haugen, K. and Schubert, M. (2014) 'UEFA financial fair play: the curseof regulation', EJSS Journal, 2(1), 33-51.

Quirk, J.P. and Fort, R.D. (1992), Pay dirt: The business of professional team sports, 2nd ed., United States: Princeton University Press.

Rottenberg, S. (1956), 'The Baseball players' labour market', Journal of Political Economy, (64), 242-258.

Sass, M. (2012), 'Long-term Competitive Balance under UEFA Financial Fair Play Regulations', Universitat Magdeburg Working Paper, 5, 1-11.

Sass, M. (2014), 'Glory Hunters, sugar Daddies, and long-term competitive balance under UEFA financial fair play', Journal of Sports Economics, 17(2), 148-158.

Schubert, M. and Könecke, T. (2015), “Classical' doping, financial doping and beyond:UEFA's financial fair play as a policy of anti-doping', International Journal of Sport Policy and Politics 7(1), 63-86.

Scully, G.W. (1989), Business of Major League baseball, United States: University of Chicago 
Press.

Solberg, H.A. and Haugen, K.K. (2010), ‘European club football: Why enormous revenues are not enough?', Sport in Society, 13(2), 329-343.

Storm, R.K. and Nielsen, K. (2012), 'Soft budget constraints in professional football', European Sport Management Quarterly, 12(2), 183-201.

Szymanski, S. (2012), 'Insolvency in English football: irrational exuberance or negative productivity shocks?', International Association of Sports Economists \& NorthAmerican Association of Sports Economists, Working Paper 12-02.

Szymanski, S. (2014), 'Fair Is Foul: A Critical Analysis of UEFA Financial Fair Play', International Journal of Sport Finance, 2014 (9), 218-229.

Szymanski, S. and Kuypers, T. (2000), Winners and losers, London: Penguin Books Canada.

Wilson, R., Plumley, D. and Ramchandani, G. (2013) 'The relationship between ownership structure and club performance in the English Premier League', Sport, Business and Management: An International Journal, 3(1), 19-36.

Winfree, J. and Fort, R. (2012), 'Nash conjectures and talent supply in sports league modeling: A comment on current modeling disagreements', Journal of Sports Economics, 13(3), 306-313.

UEFA (2010), UEFA Club Licensing and Financial Fair Play Regulations Edition 2010, Nyon, Switzerland: UEFA.

UEFA (2011), The European Club Licensing Benchmarking Report Financial Year 2011, Nyon, Switzerland: UEFA.

UEFA (2015), UEFA Club Licensing and Financial Fair Play Regulations Edition 2015, Nyon, Switzerland: UEFA.

Vopel, H. (2013), 'Is Financial Fair Play Really Justified? An Economic and Legal Assessment of UEFA's Financial Fair Play Rules', Hamburg Institute of International Economics, 79, 1-30. 


\section{Appendices}

\section{Appendix A}

Table 1: Data - Total points per season

\begin{tabular}{|c|c|c|c|c|c|c|c|c|c|c|c|c|c|c|c|c|c|c|c|c|c|}
\hline & $95 / 96$ & $96 / 97$ & $97 / 98$ & 98/99 & $99 / 00$ & $00 / 01$ & $01 / 02$ & $02 / 03$ & $03 / 04$ & $04 / 05$ & $05 / 06$ & $06 / 07$ & $07 / 08$ & $08 / 09$ & $09 / 10$ & $10 / 11$ & $11 / 12$ & $12 / 13$ & $13 / 14$ & $14 / 15$ & $15 / 16$ \\
\hline 1 & 82 & 75 & 78 & 79 & 91 & 80 & 87 & 83 & 90 & 95 & 91 & 89 & 87 & 90 & 86 & 80 & 89 & 89 & 86 & 87 & 81 \\
\hline 2 & 78 & 68 & 77 & 78 & 73 & 70 & 80 & 78 & 79 & 83 & 83 & 83 & 85 & 86 & 85 & 71 & 89 & 78 & 84 & 79 & 71 \\
\hline 3 & 71 & 68 & 65 & 75 & 69 & 69 & 77 & 69 & 75 & 77 & 82 & 68 & 83 & 83 & 75 & 71 & 70 & 75 & 82 & 75 & 70 \\
\hline 4 & 63 & 68 & 63 & 67 & 67 & 68 & 71 & 67 & 60 & 61 & 67 & 68 & 76 & 72 & 70 & 68 & 69 & 73 & 79 & 70 & 66 \\
\hline 5 & 63 & 61 & 59 & 57 & 65 & 66 & 66 & 64 & 56 & 58 & 65 & 60 & 65 & 63 & 67 & 62 & 65 & 72 & 72 & 64 & 66 \\
\hline 6 & 61 & 59 & 58 & 55 & 58 & 61 & 64 & 60 & 56 & 58 & 63 & 58 & 60 & 62 & 64 & 58 & 64 & 63 & 69 & 62 & 63 \\
\hline 7 & 61 & 57 & 57 & 54 & 58 & 57 & 53 & 59 & 53 & 55 & 58 & 56 & 58 & 53 & 63 & 54 & 56 & 61 & 64 & 60 & 62 \\
\hline 8 & 61 & 56 & 56 & 52 & 55 & 54 & 50 & 52 & 53 & 52 & 56 & 55 & 57 & 51 & 61 & 49 & 52 & 49 & 56 & 56 & 60 \\
\hline 9 & 58 & 47 & 55 & 51 & 55 & 52 & 50 & 51 & 52 & 52 & 55 & 54 & 55 & 51 & 50 & 48 & 52 & 46 & 50 & 54 & 51 \\
\hline 10 & 51 & 46 & 53 & 49 & 53 & 52 & 46 & 50 & 50 & 47 & 51 & 52 & 49 & 50 & 50 & 47 & 47 & 46 & 49 & 48 & 50 \\
\hline 11 & 50 & 46 & 52 & 47 & 52 & 51 & 45 & 49 & 48 & 46 & 50 & 50 & 46 & 45 & 47 & 47 & 47 & 44 & 45 & 47 & 47 \\
\hline 12 & 43 & 46 & 48 & 46 & 52 & 49 & 45 & 49 & 47 & 45 & 48 & 46 & 43 & 45 & 46 & 46 & 47 & 43 & 42 & 47 & 47 \\
\hline 13 & 43 & 42 & 44 & 46 & 50 & 48 & 44 & 48 & 45 & 44 & 47 & 43 & 42 & 41 & 44 & 46 & 45 & 42 & 40 & 44 & 45 \\
\hline 14 & 41 & 42 & 44 & 43 & 44 & 42 & 44 & 48 & 45 & 44 & 45 & 42 & 40 & 41 & 39 & 46 & 45 & 41 & 38 & 41 & 43 \\
\hline 15 & 40 & 42 & 44 & 42 & 44 & 42 & 43 & 47 & 44 & 42 & 43 & 41 & 39 & 41 & 38 & 43 & 43 & 41 & 38 & 39 & 42 \\
\hline 16 & 38 & 41 & 44 & 42 & 38 & 42 & 40 & 45 & 41 & 39 & 42 & 39 & 37 & 36 & 36 & 42 & 38 & 41 & 37 & 38 & 42 \\
\hline 17 & 38 & 41 & 40 & 41 & 36 & 42 & 40 & 44 & 39 & 34 & 38 & 38 & 36 & 35 & 35 & 40 & 37 & 39 & 36 & 38 & 39 \\
\hline 18 & 38 & 40 & 40 & 36 & 33 & 34 & 36 & 42 & 33 & 33 & 34 & 38 & 36 & 34 & 30 & 39 & 36 & 36 & 33 & 35 & 37 \\
\hline 19 & 33 & 39 & 35 & 35 & 31 & 34 & 30 & 26 & 33 & 33 & 30 & 34 & 35 & 32 & 30 & 39 & 31 & 28 & 32 & 33 & 34 \\
\hline , & 29 & 34 & 33 & 2 & 24 & 26 & 28 & 19 & 33 & 32 & 15 & 28 & 11 & & 19 & 33 & 25 & 25 & & 3 & \\
\hline
\end{tabular}

Source: Premier League, 2016a 
Appendix B

Table 2: Herfindahl Index, standard deviation, and Scully-Noll ratio results

\begin{tabular}{|c|c|c|c|}
\hline & 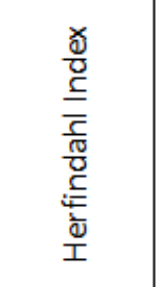 & 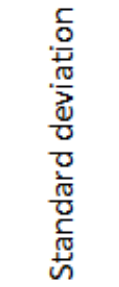 & 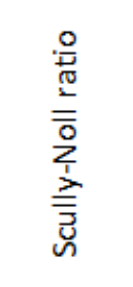 \\
\hline \begin{tabular}{|l|}
$1995 / 96$ \\
\end{tabular} & 0.054023 & 15.162 & 11.0586 \\
\hline \begin{tabular}{|c|}
$1996 / 97$ \\
\end{tabular} & 0.052659 & 12.043 & 8.9911 \\
\hline $1997 / 98$ & 0.052688 & 12.430 & 9.04024 \\
\hline $1998 / 99$ & 0.053544 & 14.000 & 10.3801 \\
\hline \begin{tabular}{|l|}
$1999 / 00$ \\
\end{tabular} & 0.054464 & 16.064 & 11.6492 \\
\hline $2000 / 01$ & 0.053436 & 13.972 & 10.2199 \\
\hline $2001 / 02$ & 0.054901 & 16.687 & 12.2064 \\
\hline $2002 / 03$ & 0.054046 & 15.323 & 11.0908 \\
\hline $2003 / 04$ & 0.054110 & 15.178 & 11.1773 \\
\hline $2004 / 05$ & 0.055227 & 17.083 & 12.6052 \\
\hline $2005 / 06$ & 0.055824 & 18.610 & 13.3056 \\
\hline $2006 / 07$ & 0.054397 & 15.851 & 11.5612 \\
\hline \begin{tabular}{|l|}
$2007 / 08$ \\
\end{tabular} & 0.056842 & 19.735 & 14.4218 \\
\hline $2008 / 09$ & 0.055808 & 18.236 & 13.288 \\
\hline $2009 / 10$ & 0.056318 & 18.873 & 13.8586 \\
\hline $2010 / 11$ & 0.052931 & 12.779 & 9.43863 \\
\hline $2011 / 12$ & 0.055271 & 17.439 & 12.659 \\
\hline $2012 / 13$ & 0.055664 & 17.819 & 13.1225 \\
\hline $2013 / 14$ & 0.056258 & 19.273 & 13.7926 \\
\hline $2014 / 15$ & 0.054633 & 16.349 & 11.8675 \\
\hline $2015 / 16$ & 0.054244 & 15.438 & 11.3584 \\
\hline
\end{tabular}


Appendix C

Table 3: Range data

\begin{tabular}{|c|c|c|c|c|c|c|c|c|}
\hline & $\begin{array}{l}\underline{E} \\
\frac{E}{E} \\
\frac{E}{E} \\
\sum\end{array}$ & 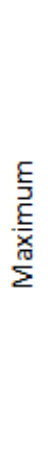 & $\stackrel{\substack{\mathbb{\varpi} \\
\Sigma}}{\sum}$ & 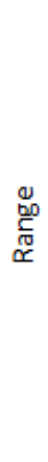 & 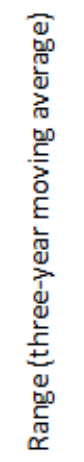 & 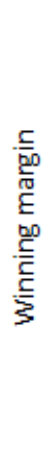 & 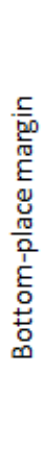 & 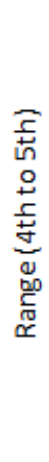 \\
\hline $1995 / 96$ & 29 & 82 & 52.10 & 53 & & 4 & 4 & 0 \\
\hline $1996 / 97$ & 34 & 75 & 50.90 & 41 & & 7 & 5 & 7 \\
\hline $1997 / 98$ & 33 & 78 & 52.25 & 45 & 46.33 & 1 & 2 & 4 \\
\hline $1998 / 99$ & 30 & 79 & 51.25 & 49 & 45.00 & 1 & 5 & 10 \\
\hline $1999 / 00$ & 24 & 91 & 52.40 & 67 & 53.67 & 18 & 7 & 2 \\
\hline $2000 / 01$ & 26 & 80 & 51.95 & 54 & 56.67 & 10 & 8 & 2 \\
\hline $2001 / 02$ & 28 & 87 & 51.95 & 59 & 60.00 & 7 & 2 & 5 \\
\hline $2002 / 03$ & 19 & 83 & 52.50 & 64 & 59.00 & 5 & 7 & 3 \\
\hline $2003 / 04$ & 33 & 90 & 51.60 & 57 & 60.00 & 11 & 0 & 4 \\
\hline $2004 / 05$ & 32 & 95 & 51.50 & 63 & 61.33 & 12 & 1 & 3 \\
\hline $2005 / 06$ & 15 & 91 & 53.15 & 76 & 65.33 & 8 & 15 & 2 \\
\hline $2006 / 07$ & 28 & 89 & 52.10 & 61 & 66.67 & 6 & 6 & 8 \\
\hline $2007 / 08$ & 11 & 87 & 52.00 & 76 & 71.00 & 2 & 24 & 11 \\
\hline $2008 / 09$ & 32 & 90 & 52.15 & 58 & 65.00 & 4 & 0 & 9 \\
\hline $2009 / 10$ & 19 & 86 & 51.75 & 67 & 67.00 & 1 & 11 & 3 \\
\hline $2010 / 11$ & 33 & 80 & 51.45 & 47 & 57.33 & 9 & 6 & 6 \\
\hline $2011 / 12$ & 25 & 89 & 52.35 & 64 & 59.33 & 0 & 6 & 4 \\
\hline $2012 / 13$ & 25 & 89 & 51.60 & 64 & 58.33 & 11 & 3 & 1 \\
\hline $2013 / 14$ & 30 & 86 & 53.10 & 56 & 61.33 & 2 & 2 & 7 \\
\hline $2014 / 15$ & 30 & 87 & 52.35 & 57 & 59.00 & 8 & 3 & 6 \\
\hline $2015 / 16$ & 17 & 81 & 51.65 & 64 & 59.00 & 10 & 17 & 0 \\
\hline
\end{tabular}




\section{Appendix D}

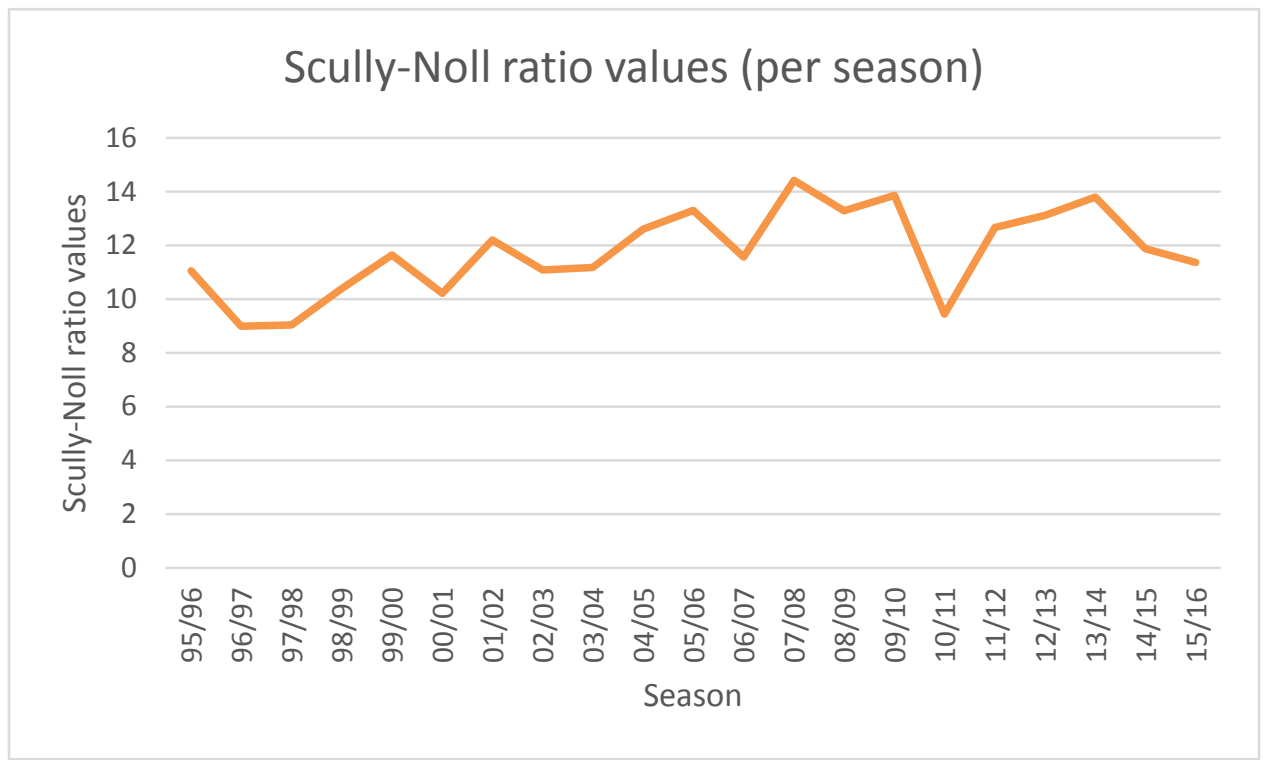

Figure 8: Scully-Noll ratio values

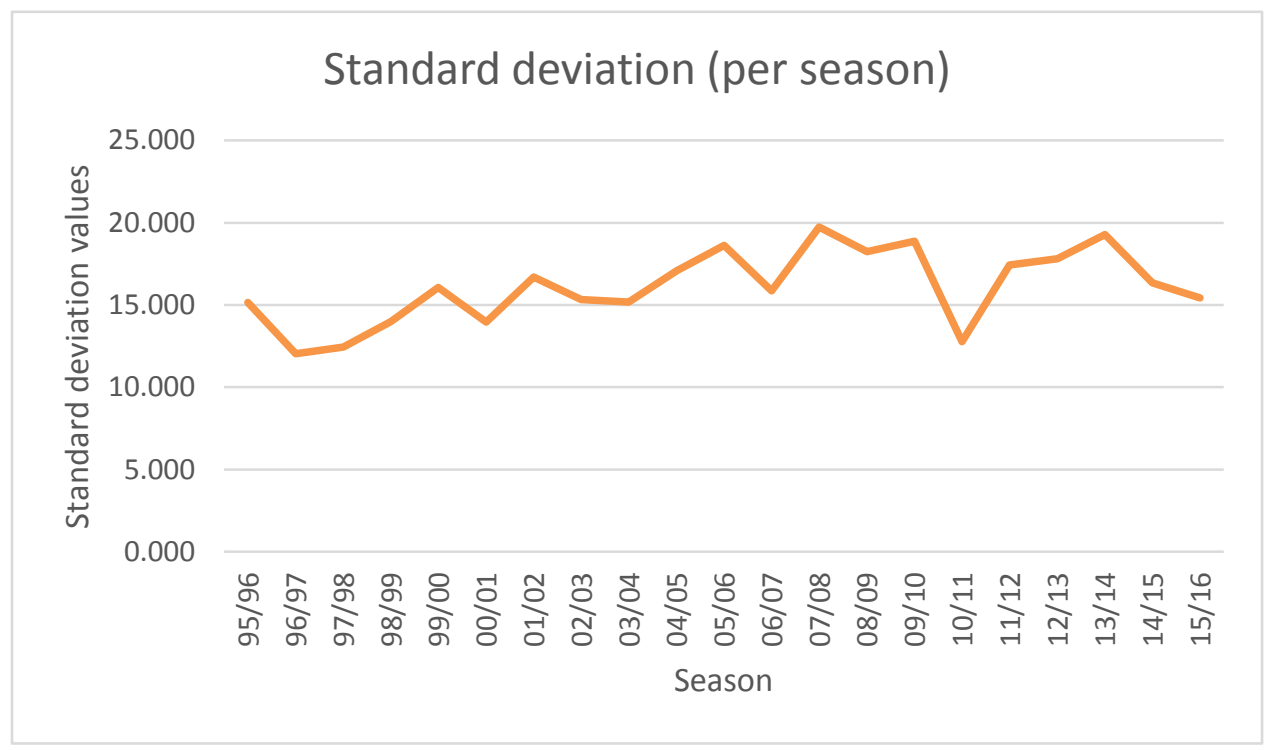

Figure 9: Standard deviation values 